\title{
Converging toward a common speech code: imitative and perceptuo-motor recalibration processes in speech production
}

\author{
Marc Sato $^{1 *}$, Krystyna Grabski ${ }^{2}$, Maëva Garnier ${ }^{1}$, Lionel Granjon ${ }^{3}$, Jean-Luc Schwartz ${ }^{1}$ and \\ Noël Nguyen ${ }^{4}$
}

\author{
1 Grenoble Images Parole Signal Automatique-LAB, Département Parole and Cognition, Centre National de la Recherche Scientifique, Grenoble Université, \\ Grenoble, France \\ ${ }^{2}$ Centre for Research on Brain, Language and Music, McGill University, Montreal, QC, Canada \\ ${ }^{3}$ Laboratoire Psychologie de la Perception, Centre National de la Recherche Scientifique, École Normale Supérieure, Paris, France \\ ${ }^{4}$ Laboratoire Parole and Langage, Centre National de la Recherche Scientifique, Aix-Marseille Université, Aix-en-Provence, France
}

\section{Edited by:}

Jennifer Pardo, Montclair State

University, USA

\section{Reviewed by:}

John F. Houde, University of California, San Francisco, USA

Eric Vatikiotis-Bateso, University of British Columbia, Canada

*Correspondence:

Marc Sato, Département Parole and Cognition, Grenoble Images Parole Signal Automatique-LAB, UMR CNRS 5216, Grenoble Université, 1180, Avenue Centrale, BP 25, 38040 Grenoble Cedex 9, France e-mail:marc.sato@gipsa-lab.inpg.fr
Auditory and somatosensory systems play a key role in speech motor control. In the act of speaking, segmental speech movements are programmed to reach phonemic sensory goals, which in turn are used to estimate actual sensory feedback in order to further control production. The adult's tendency to automatically imitate a number of acoustic-phonetic characteristics in another speaker's speech however suggests that speech production not only relies on the intended phonemic sensory goals and actual sensory feedback but also on the processing of external speech inputs. These online adaptive changes in speech production, or phonetic convergence effects, are thought to facilitate conversational exchange by contributing to setting a common perceptuo-motor ground between the speaker and the listener. In line with previous studies on phonetic convergence, we here demonstrate, in a non-interactive situation of communication, online unintentional and voluntary imitative changes in relevant acoustic features of acoustic vowel targets (fundamental and first formant frequencies) during speech production and imitation. In addition, perceptuo-motor recalibration processes, or after-effects, occurred not only after vowel production and imitation but also after auditory categorization of the acoustic vowel targets. Altogether, these findings demonstrate adaptive plasticity of phonemic sensory-motor goals and suggest that, apart from sensory-motor knowledge, speech production continuously draws on perceptual learning from the external speech environment.

Keywords: phonetic convergence, imitation, speech production, speech perception, sensory-motor interactions, internal models, perceptual learning

\section{INTRODUCTION}

Speech production is a complex multistage motor process that requires phonetic encoding, initiation and coordination of sequences of supra-laryngeal and laryngeal movements produced by the combined actions of the pulmonary/respiratory system, the larynx and the vocal tract. Influential models of speech motor control postulate that auditory and somatosensory representations also play a key role in speech production. It is proposed that segmental speech movements are programmed to reach phonemic auditory and somatosensory goals, which in turn are used to estimate actual sensory inputs during speech production (for reviews, Perkell et al., 1997, 2000; Perrier, 2005, 2012; Guenther, 2006; Guenther and Vladusich, 2012; Perkell, 2012). The relationships between speech motor commands and sensory feedback are thought to be progressively learned by the central nervous system during native (and foreign) language acquisition, leading to the establishment of mature phonemic sensory-motor goals.
In adult/fluent speech production, a large number of studies employing manipulations of both somatosensory and auditory feedback also support the hypothesis that sensory feedback plays an important role in tuning speech motor control. For instance, transient transformations of both the auditory and somatosensory feedback, due to unexpected dynamical mechanical loading of supra-laryngeal articulators, result in on-line and rapid articulatory adjustments in speech production (Folkins and Abbs, 1975; Abbs and Gracco, 1984; Gracco and Abbs, 1985). Similarly, online modifications of the auditory feedback in its pitch (Elman, 1981; Burnett et al., 1998; Jones and Munhall, 2000), vowel formant frequencies (Houde and Jordan, 1998; Jones and Munhall, 2000; Houde et al., 2002; Purcell and Munhall, 2006a,b; Cai et al., 2011; Rochet-Capellan and Ostry, 2011, 2012) or fricative first spectral moment (Shiller et al., 2009, 2010) also induce compensatory changes in speech production. Finally, although auditory information is often assumed to be the dominant sensory modality, the integration of somatosensory information in 
the achievement of speech movements has also been demonstrated (Tremblay et al., 2003; Nasir and Ostry, 2006; Feng et al., 2011; Lametti et al., 2012). Importantly, these studies not only demonstrate online motor corrections to counteract the effect of perturbations, but also a persistence of those corrections (i.e., an after-effect) once the perceptual manipulation is removed (Houde and Jordan, 1998; Jones and Munhall, 2000; Houde et al., 2002; Tremblay et al., 2003; Nasir and Ostry, 2006; Purcell and Munhall, 2006b; Shiller et al., 2009). The fact that motor compensatory adjustments do not disappear immediately likely reflects a global temporary remapping, or re-calibration, of the sensory-motor relationships.

Due to the intrinsic temporal limitations of the biological feedback systems, the concepts of efference copy (von Holst and Mittelstaedt, 1950) and internal models (Francis and Wonham, 1976; Kawato et al., 1987) have been introduced in order to explain how the central nervous system rapidly reacts to perturbations and adjusts fine-grained motor parameters (Guenther, 1995; Perkell et al., 1997; Guenther et al., 1998; Houde and Jordan, 1998; for recent reviews, see Perkell et al., 2000; Guenther, 2006; Hickok et al., 2011; Houde and Nagarajan, 2011; Guenther and Vladusich, 2012; Hickok, 2012; Perkell, 2012; Perrier, 2012).

During language acquisition, perceptuo-motor goals that define successful speech motor acts are thought to be gradually explored and acquired in interaction with adult speakers (Kuhl and Meltzoff, 1996; Kuhl et al., 1997; Kuhl, 2004). The relationships between speech motor commands and sensory feedback signals are then progressively learned by the central nervous system, and stored in the form of an internal forward model. The internal forward model allows for the prediction of the sensory consequences of speech motor movements in relation with the intended sensory speech goals. These internal sensory predictions, generated prior to the actual motor execution and sensory feedback, can assist in speech motor control. In case of discrepancy between the internal sensory predictions and the actual sensory feedback, corrective motor commands are estimated in order to further control production. Such corrective motor commands from the internal forward model allow refining and updating the relationships between the intended sensory speech goals and the relevant sequence of motor commands, which are then stored in an internal inverse model. Once the inverse model has been learned, it is hypothesized that speech production, in mature/fluent speech and in normal circumstances, operates almost entirely under the internal inverse model and feedforward control mechanisms (for recent reviews, see Guenther and Vladusich, 2012; Perkell, 2012; Perrier, 2012). From that view, the intended phonemic sensory goal allows the internal inverse model to internally specify the relevant speech motor sequences, without involvement of the internal forward model and sensory feedback control mechanisms, thus compensating for the delay inherent in sensory feedback. On the other hand, sensory feedback can still be used for online corrective motor adjustments, in case of external perturbations, in the comparison between internal sensory predictions from the forward model and actual sensory inputs.

The above-mentioned studies and models demonstrate a key role of on-line auditory and somatosensory feedback control mechanisms in speech production and suggest that speech goals are defined in multi-dimensional motor, auditory and somatosensory spaces. However, for all their importance, these studies fail to reveal the extent to which speech perception and production systems may be truly integrated when speaking. First, individual differences in perceptual capacities may also act on speech production. From that view, a recent study on healthy adults, with no reported impairment of hearing or speech, demonstrates that individual differences in auditory discrimination abilities influence the degree to which speakers adapt to altered auditory feedback (Villacorta et al., 2007; but see Feng et al., 2011). Second, many studies of adaptation in speech production have focused primarily on the flexibility of motor processes, without regard for possible adaptive changes of phonemic sensory representations that are presumed to constitute the sensory goals of speech movements (except during language acquisition and the learning of internal models). However, two studies involving altered auditory or somatosensory feedback show compensatory changes not only in production of a speech sound, but also in its perception (Nasir and Ostry, 2009; Shiller et al., 2009). These results thus suggest plasticity of phonemic sensory representations in relation to adjustment of motor commands. Finally, the adult's tendency to automatically imitate a number of acoustic-phonetic characteristics in another speaker's speech suggests that speech production relies not only on the intended phonemic sensory goals and actual sensory feedback but also on the processing of external speech inputs.

In keeping with this later finding, the present study aimed at investigating adaptive plasticity of phonemic sensory-motor goals in speech production, based on either unintentional or voluntary vowel imitation. In addition to speech motor control, the working hypothesis of the present study capitalizes on previous studies on perceptual learning and speech imitation as well as on the theoretical proposal of a functional coupling between speech perception and action systems.

In this framework, it is worthwhile noting that speech and vocal imitation is one of the basic mechanisms governing the acquisition of spoken language by children (Kuhl and Meltzoff, 1996; Kuhl et al., 1997; Kuhl, 2004). In adults, unintentional speech imitation, or phonetic convergence, has been found to also occur in the course of a conversational interaction (for recent reviews, see Babel, 2009; Aubanel, 2011; Lelong, 2012). The behavior of each talker can evolve with respect to that of the other talker in two opposite directions: it may become more similar to the other talker's behavior (a phenomenon referred to as convergence) or more dissimilar. Convergence effects have been shown to be systematic and recurrent, and manifest themselves under many different forms, including posture (Shockley et al., 2003), head movements and facial expressions (Estow et al., 2007; Sato and Yoshikawa, 2007) and, regarding speech, vocal intensity (Natale, 1975; Gentilucci and Bernardis, 2007), speech rate (Giles et al., 1991; Bosshardt et al., 1997), voice onset time (Flege, 1987; Flege and Eefting, 1987; Sancier and Fowler, 1997; Fowler et al., 2008), fundamental frequency, and pitch curve (Gregory, 1986; Gregory et al., 1993; Bosshardt et al., 1997; Kappes et al., 2009; Babel and Bulatov, 2012), formant frequencies and spectral distributions (Gentilucci and Cattaneo, 2005; Delvaux and Soquet, 
2007; Gentilucci and Bernardis, 2007; Aubanel and Nguyen, 2010; Lelong and Bailly, 2011). Apart from directly assessing phonetic convergence on acoustic parameters, other studies measured convergence by means of perceptual judgments, mostly using AXB tests (Goldinger, 1998; Goldinger and Azuma, 2004; Pardo, 2006; Pardo et al., 2010; Kim et al., 2011). Importantly, phonetic convergence has been shown to manifest in a variety of ways. Some involve natural settings, as during conversational exchange when exposure to the speech of others leads to phonetic convergence with that speech (Natale, 1975; Pardo, 2006; Aubanel and Nguyen, 2010; Pardo et al., 2010; Kim et al., 2011; Lelong and Bailly, 2011), or when exposure to a second language influences speech production of a native language, and vice-versa (Flege, 1987; Flege and Eefting, 1987; Sancier and Fowler, 1997; Fowler et al., 2008). Other involve non-interactive situations of communication, as when hearing and/or seeing a recorded speaker influences the production of similar or dissimilar speech sounds (Goldinger and Azuma, 2004; Gentilucci and Cattaneo, 2005; Delvaux and Soquet, 2007; Gentilucci and Bernardis, 2007; Kappes et al., 2009; Babel and Bulatov, 2012). Altogether, these phenomena of "speech accommodation" may facilitate conversational exchange by contributing to setting a common ground between speakers (Giles et al., 1991). In that respect, they may have the same effect as so-called alignment mechanisms, which are assumed to apply to linguistic representations at different levels between partners, in order for these partners to have a better joint understanding of what they are talking about (Garrod and Pickering, 2004; Pickering and Garrod, 2004, 2007).

Apart from social attunement, can phonetic convergence be also explained at a more basic sensory-motor level? In our view, phonetic convergence necessarily involves complex sensorimotor interactions that allow the speaker to compare or tune his/her own sensory and motor speech repertoire with the phonetic characteristics of the perceived utterance. Since phonetic convergence implies perception of speech sounds prior to actual speech production, phonetic convergence is likely to first rely on perceptual processing and learning from the external speech environment, leading to adaptive plasticity of phonemic sensory goals.

From that view, a significant body of speech perception research has demonstrated that sensory representations of speech sounds are flexible in response to changes in the sensory and linguistic aspects of speech input (e.g., Ladefoged and Broadbent, 1957; Miller and Liberman, 1979; Mann and Repp, 1980). In addition, studies on perceptual learning, or perceptual recalibration, have provided evidence for increased performance in speech perception/recognition and changes in perceptual representations after exposure to only a few speech sounds (e.g., Nygaard and Pisoni, 1998; Bertelson et al., 2003; Norris et al., 2003; Clarke and Garrett, 2004; Kraljic and Samuel, 2005, 2006, 2007; McQueen et al., 2006; Bradlow and Bent, 2008). In addition to perceptual learning, it is also to note that several psycholinguistic and neurobiological models of speech perception argue that phonetic interpretation of sensory speech inputs is determined, or at least partly constrained, by articulatory procedural knowledge (Liberman et al., 1967; Liberman and Mattingly, 1985; Fowler, 1986; Liberman and Whalen, 2000; Schwartz et al., 2002,
2012; Scott and Johnsrude, 2003; Callan et al., 2004; Galantucci et al., 2006; Wilson and Iacoboni, 2006; Skipper et al., 2007; Rauschecker and Scott, 2009). These models postulate that sensorimotor interactions play a key role in speech perception, with the motor system thought to partly constrain phonetic interpretation of the sensory inputs through the internal generation of candidate articulatory categories. Taken together, these studies and models thus suggest that listeners maintain perceptual and motor representations that incorporate fine-grained information about specific speech sounds, speakers, and situations. Hence, during speech production, phonetic convergence may arise from induced plasticity of phonemic sensory and motor representations, in relation to relevant adjustment of motor commands.

To extend the above-mentioned findings on phonetic convergence and to further test adaptive plasticity of phonemic sensorymotor goals in speech production, the present study aimed at investigating, in a non-interactive situation of communication, both unintentional and voluntary imitative changes in relevant acoustic features of acoustic vowel targets during speech production and imitation. A second goal of this study was to test offline perceptuo-motor recalibration processes (i.e., after-effects) after vowel production, imitation, and categorization.

\section{METHODS \\ PARTICIPANTS}

Three groups of twenty-four healthy adults, native French speakers, participated in the production, imitation and categorization experiments ( 12 females and 12 males per group). In order to test possible relationships between phonetic convergence and voluntary imitation, a subgroup of 12 subjects ( 6 females and 6 males) participated in both the production and imitation experiments (see Procedure). All participants had normal or corrected-tonormal vision, and reported no history of speaking, hearing or motor disorders.

\section{STIMULI}

Multiple utterances of $/ \mathrm{i} /, / \mathrm{e} /$, and $/ \varepsilon /$ steady-state French vowels were individually produced from a visual orthographic target and recorded by six native French speakers (3 females and 3 males) in a sound-attenuated room. In order to cover the typical range of $F_{0}$ values during vowel production for male and female speakers, the six speakers were selected with respect to their largely distinct fundamental frequency $\left(F_{0}\right)$ values during vowel production (see below). None of the speakers participated in the three experiments.

Throughout this study, the focus was put on the main determinant of the voice characteristics that is $F_{0}$, leaving aside a number of other possible acoustic parameters that could also provide targets for convergence phenomena (e.g., voice quality, $F_{0}$ variations inside the spoken utterances, intensity, duration, etc.). In the same vein, the focus was comparatively put on one of the main characteristic of vowels' phonetic quality that is $F_{1}$, considering that in the set of unrounded front vowels here used, $F_{1}$ is both the basic cue to distinguishing these vowels from one another (see for example Ménard et al., 2002), and shows large variations from one French speaker to another (e.g., Ménard et al., 2008). 
This also leaves aside a number of other acoustic determinants of phonetic quality such as $F_{2}$, but also $F_{3}$ which is known to play an important role in the front unrounded region, particularly for /i/ and to a lesser extent for /e/. The choice to focus on acoustic variables a priori considered as the main characteristics in each domain seemed adequate in order to focus on major phenomena and escape from difficult — and largely unsolved-questions associated with the weighing of perceptual cues in a given perceptual domain.

One token of each vowel was selected per speaker and digitized in an individual sound file at a sampling rate of $44.1 \mathrm{kHz}$ with 16bit quantization recording. Using Praat software (Boersma and Weenink, 2013), each vowel was scaled to $75 \mathrm{~dB}$ and cut, at zero crossing points, from the vocalic onset to $250 \mathrm{~ms}$ following it. $F_{0}$ and first formant $\left(F_{1}\right)$ values were then calculated for each vowel from a period defined as $\pm 25 \mathrm{~ms}$ of the maximum peak intensity (see Table 1 ). With this procedure, the stimuli differed in $F_{0}$ and $F_{1}$ values according to both gender and speaker (mean $F_{0}$ averaged across vowels: $100-120-136 \mathrm{~Hz}$ and $196-249-296 \mathrm{~Hz}$ for the three male and the three female speakers, respectively; mean $F_{1}$ for /i/, /e/, and / $\varepsilon /$ vowels: $258-314-496 \mathrm{~Hz}$ and 285$414-646 \mathrm{~Hz}$ for the three male and the three female speakers, respectively).

\section{EXPERIMENTAL PROCEDURE}

The three experiments were carried out in a sound-proof room. Participants sat in front of a computer monitor at a distance of approximately $50 \mathrm{~cm}$. The acoustic stimuli were presented at a comfortable sound level through a loudspeaker, with the same sound level set for all participants. The Presentation software (Neurobehavioral Systems, Albany, CA) was used to control the stimulus presentation during all experiments, and to record key responses in the categorization experiment (see below). All participants' productions were recorded for off-line analyses. The experimental design and apparatus were identical in all experiments, except the task required during the presentation of the acoustic stimuli (i.e., vowel production, vowel imitation and vowel categorization; see Figure 1).

- Production experiment: The experiment was designed to test phonetic convergence on acoustically presented vowels

Table $1 \mid F_{0}$ and $F_{1}$ values of $/ \mathrm{i} /, / \mathrm{e} /, / \varepsilon /$ target vowels according to the six recorded speakers ( 3 females/males).

\begin{tabular}{|c|c|c|c|c|c|c|c|}
\hline \multirow[t]{2}{*}{ Vowel } & \multirow[t]{2}{*}{ Gender } & \multicolumn{3}{|c|}{$F_{0}$} & \multicolumn{3}{|c|}{$F_{1}$} \\
\hline & & S1 & S2 & S3 & S1 & S2 & S3 \\
\hline /i/ & Female & 210 & 251 & 288 & 285 & 269 & 301 \\
\hline /e/ & Female & 190 & 248 & 290 & 389 & 399 & 453 \\
\hline \multirow[t]{2}{*}{$|\varepsilon|$} & Female & 187 & 249 & 284 & 693 & 577 & 668 \\
\hline & & S4 & S5 & S6 & S4 & S5 & S6 \\
\hline /i/ & Male & 137 & 120 & 103 & 278 & 248 & 247 \\
\hline /e/ & Male & 139 & 120 & 98 & 390 & 324 & 228 \\
\hline$\varepsilon /$ & Male & 132 & 121 & 100 & 510 & 440 & 538 \\
\hline
\end{tabular}

and to measure the magnitude of such online automatic imitative changes as well as possible offline perceptuo-motor recalibration due to phonetic convergence (after-effects). To this aim, participants were instructed to produce distinct vowels $(/ \mathrm{i} /$, /e/, or $/ \varepsilon /)$, one at a time, according to either a visual orthographic or an acoustic vowel target. Importantly, no instructions to "repeat" or to "imitate" the acoustic targets were given to the participants. Moreover, all participants were naive as to the purpose of the experiment. A block design was used where participants produced vowels according first to orthographic targets (baseline), then to acoustic targets (phonetic convergence) and finally to orthographic targets (after-effect). This procedure allowed comparing participants' productions 1) between the first presentation of the orthographic targets and the following presentation of the acoustic targets in order to determine possible convergence effects on $F_{0}$ and $F_{1}$ values according to the acoustic targets and 2) between the first and last presentations of the orthographic targets in order to determine possible after-effects.

- Imitation experiment: To compare phonetic convergence and voluntary imitation of the acoustic vowels, the second group of participants performed the same experiment except that they were explicitly asked to imitate the acoustic targets. The only indication given to the participants was to imitate the voice characteristics of the perceived speaker.

- Categorization experiment: The third experiment was designed to test whether after-effects can occur without prior unintentional/automatic or voluntary vowel imitation but after auditory categorization of the acoustic targets. To this aim, participants were instructed to produce vowels according to the orthographic targets and to manually categorize the acoustic vowel targets, without overt production. During the categorization task, participants were instructed to produce a motor response by pressing with their right hand, one of three keys corresponding to the $/ \mathrm{i} /, / \mathrm{e} /$, or $/ \varepsilon /$ vowels, respectively.

Each experiment consisted of three experimental blocks, involving the acoustic targets previously recorded by either the three female or the three male speakers. In each block, the /i/, $/ e /$, and $/ \varepsilon /$ acoustic targets were related to a single speaker. With this procedure, $F_{0}$ values of the vowel targets remained similar within each block while $F_{1}$ varied according to each vowel type. The block order (across the three speakers) was fully counterbalanced across participants. In each experiment, six female and six male participants were presented with acoustic targets from the female speakers and six female and six male participants were presented with acoustic targets from the male speakers. This procedure allowed testing possible differences in imitative changes and after-effects depending on participant's and speaker's acoustic space congruency (i.e., female/female and male/male vs. female/male and male/female participants/ speakers).

Each experimental block consisted of the orthographic presentation of the three vowels (presented 5 times in a random order) then the acoustic presentation of the three vowels (randomly presented 10 times) and finally the orthographic presentation of the three vowels (randomly presented 5 times). 


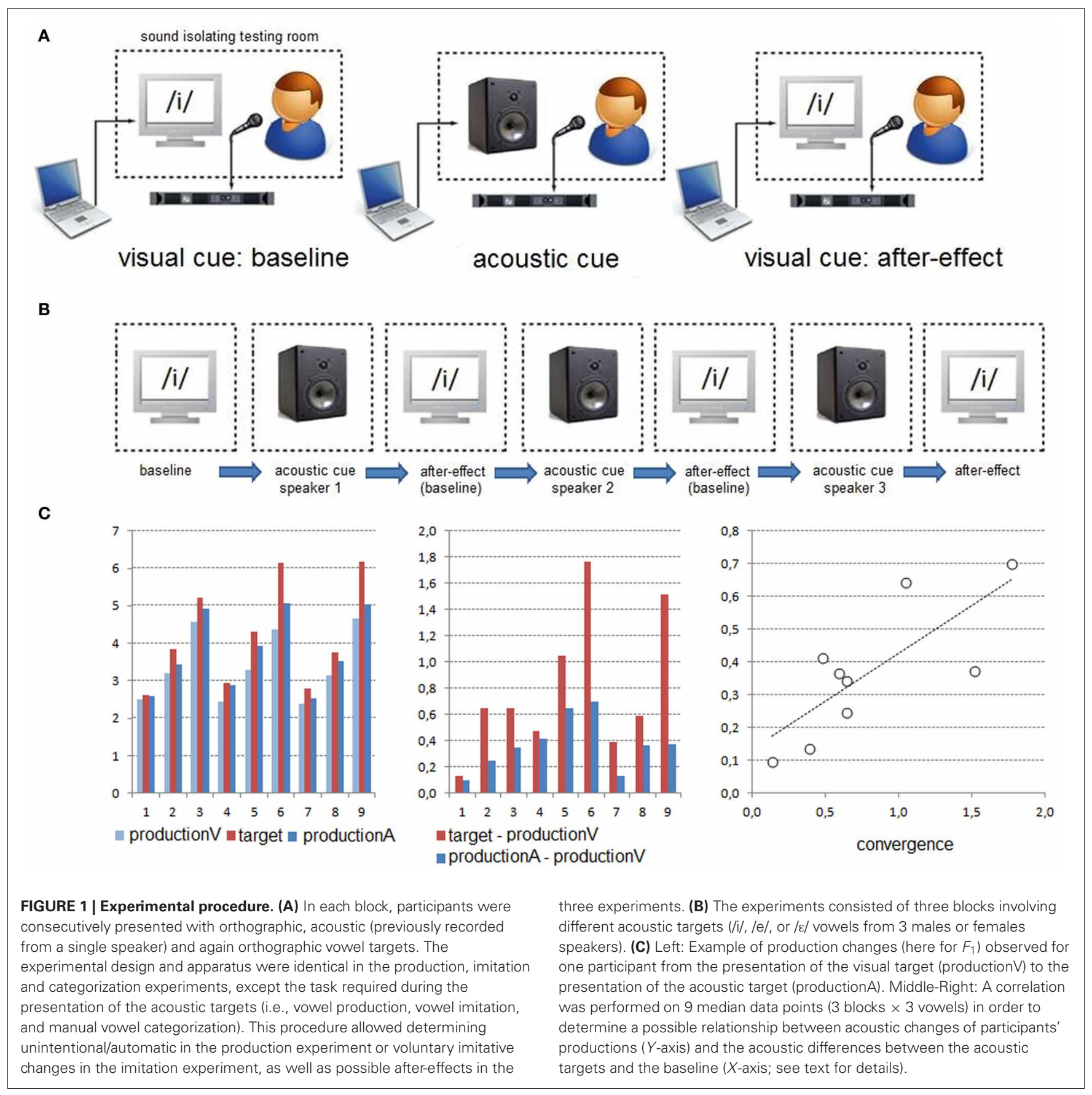

Since perceptual learning from the external speech environment likely operated throughout the experiment, the last orthographic presentation of the vowels served as the first sub-block in the following experimental block. In each sub-block, each trial started with an orthographic or an acoustic target for $250 \mathrm{~ms}$, a blank screen for $500 \mathrm{~ms}$, a fixation cue (the "+" symbol) presented in the middle of the screen for $250 \mathrm{~ms}$, and ended with a blank screen for $2000 \mathrm{~ms}$. In order to limit possible close-shadowing effects (Porter and Lubker, 1980), participants were instructed to produce their response only after the presentation of the "+" symbol. Hence, the intertrial interval was $3 \mathrm{s.}$

The total duration of each experiment was around $10 \mathrm{~min}$. The experiments were preceded by a brief training session. A debriefing was carried out at the end of each experiment. Importantly, none of the participants reported having voluntarily imitated the acoustic stimuli in the production experiment. Note that the subgroup of subjects who participated in both the production and imitation experiments, always first performed the production experiment first. 


\section{ACOUSTIC ANALYSES}

All acoustic analyses were performed using Praat software. A semi-automatic procedure was first devised for segmenting participants' recorded vowels (8640 utterances). For each participant, the procedure involved the automatic segmentation of each vowel based on an intensity and duration algorithm detection. Based on minimal duration and low intensity energy parameters, the algorithm automatically identified pauses between each vowel and set the vowel's boundaries on that basis. If necessary, these boundaries were hand-corrected, based on waveform and spectrogram information. Omissions, wrong productions and hesitations were manually identified and removed from the analyses. Finally, for each vowel, $F_{0}$ and $F_{1}$ values were calculated from a period defined as $\pm 25 \mathrm{~ms}$ of the maximum peak intensity of the sound file.

The mean percentage of errors was $2.8,1.2$, and $1.2 \%$ in the production, imitation, and categorization experiments, respectively, with no participant exceeding the error limit of $10 \%$. For each experiment, median $F_{0}$ and $F_{1}$ values calculated on all participants' productions confirmed a standard distribution for the $/ \mathrm{i} /, / \mathrm{e} /$, and $/ \varepsilon /$ French vowels, with differences mainly due to gender (see Table 2).

\section{RESULTS}

For each participant and each sub-block, median $F_{0}$ and $F_{1}$ values were first computed for the /i/, /e/, and / $/$ / vowels and expressed in bark [i.e., $\arctan (0.00076 f)+3.5 \arctan \left((f / 7500)^{2}\right)$; Zwicker and Fastl, 1990]. For each experiment, median $F_{0}$ and $F_{1}$ exceeding \pm 2 standard deviations $(S D$; computed on the set of median values for the 24 participants) were removed from the analyses.

\section{PHONETIC CONVERGENCE AND VOLUNTARY IMITATION (PRODUCTION AND IMITATION EXPERIMENTS, SEE FIGURE 2)}

We here tested whether unintentional and voluntary imitation would result in shifting $F_{0}$ and/or $F_{1}$ toward the corresponding value for the acoustic target. To this aim, we first calculated acoustic changes of participants' productions between the presentation of acoustic targets and visual targets (baseline). For each participant and block, median $F_{0}$ and $F_{1}$ values produced in the baseline (i.e., median $F_{0}$ and $F_{1}$ values produced in the preceding sub-block during the presentation of the corresponding orthographic targets) were subtracted from those produced during the

\begin{tabular}{|c|c|c|c|c|c|c|c|}
\hline \multirow[t]{2}{*}{ Vowel } & \multirow[t]{2}{*}{ Gender } & \multicolumn{2}{|c|}{ Experiment A } & \multicolumn{2}{|c|}{ Experiment B } & \multicolumn{2}{|c|}{ Experiment $\mathrm{C}$} \\
\hline & & $F_{0}$ & $F_{1}$ & $F_{0}$ & $F_{1}$ & $F_{0}$ & $F_{1}$ \\
\hline /i/ & Female & 225 & 277 & 221 & 295 & 222 & 276 \\
\hline /e/ & Female & 220 & 416 & 216 & 417 & 215 & 407 \\
\hline$|\varepsilon|$ & Female & 214 & 613 & 211 & 610 & 210 & 607 \\
\hline /i/ & Male & 128 & 277 & 124 & 270 & 130 & 269 \\
\hline le/ & Male & 125 & 372 & 120 & 366 & 126 & 365 \\
\hline$|\varepsilon|$ & Male & 123 & 508 & 119 & 522 & 125 & 545 \\
\hline
\end{tabular}

presentation of each type of acoustic targets (i.e., /i/, /e/, or / $/ /$ ). Next, we calculated acoustic changes between the acoustic targets and the baseline. These two sets of data, calculated on both $F_{0}$ and $F_{1}$ values, were then correlated in order to determine a possible relationship between acoustic changes of participants' productions and the acoustic differences between the acoustic targets and the baseline (see Figure 1C). For each participant, one set of 9 correlation-points (from 3 blocks and 3 vowels) was therefore calculated for both $F_{0}$ and $F_{1}$ and one single subject slope coefficient for each acoustic parameter was estimated from these values by means of linear regressions. In order to keep the data sets homogeneous, slope coefficients exceeding \pm 2 SD were removed from the following analyses (corresponding to one participant in both the production and imitation experiments for $F_{0}$, and two and one participants in the production and imitation experiments, respectively, for $F_{1}$, see Figure 2 ).

For both $F_{0}$ and $F_{1}$ slope coefficients, the remaining data were entered into analyses of variance (ANOVA) with the experiment (phonetic convergence, imitation) and the acoustic space congruency (same vs. different gender of the model speaker and the participant) as between-subject variables. In addition, individual one-tailed $t$-tests were performed for each experiment in order to test whether the mean slope coefficient was significantly superior to zero. Finally, in order to test whether imitative changes on $F_{0}$ and $F_{1}$ may correlate, a Pearson's correlation analysis was performed between single subject slope coefficients on $F_{0}$ and $F_{1}$ for each experiment.

For $F_{0}$, ANOVA on single subject slope coefficients showed a significant effect of the task $\left[F_{(1,42)}=27.16, p<0.001\right]$, with stronger imitative changes according to the acoustic targets during the imitation task compared to the production task (mean slope coefficients of 0.08 and 0.48 in the production and imitation experiments). No effect of the acoustic space congruency $\left[F_{(1,42)}=0.05\right]$ nor task $\times$ acoustic-space congruency interaction $\left[F_{(1,42)}=0.01\right]$ were however observed. In addition, slope coefficients differed significantly from zero in both the production $\left[t_{(22)}=3.99, p<0.001\right]$ and imitation $\left[t_{(22)}=7.11, p<\right.$ $0.001]$ experiments.

For $F_{1}$, there was also a significant effect of the task $\left[F_{(1,41)}=\right.$ 4.95, $p<0.04]$, with stronger imitative changes during the imitation task compared to the production task (mean slope coefficients of 0.04 and 0.13 in the production and imitation experiments). As for $F_{0}$, no effect of the acoustic space congruency $\left[F_{(1,41)}=0.24\right]$ nor task $\times$ acoustic-space congruency interaction $\left[F_{(1,41)}=0.45\right]$ were observed. Slope coefficients also differed significantly from zero in both the production $\left[t_{(21)}=2.78\right.$, $p<0.02]$ and imitation $\left[t_{(22)}=4.21, p<0.001\right]$ experiments.

In addition, Pearson's correlation analyses showed no significant correlation between single subject slope coefficients observed for imitative changes on $F_{0}$ and $F_{1}$ in both the production $(r=0.08$, slope $=0.06)$ and imitation $(r=0.03$, slope $=0.01)$ experiments.

In sum, for both $F_{0}$ and $F_{1}$ values, these results demonstrate online imitative changes according to the acoustic vowel targets during production and imitation tasks, with stronger imitative changes in the voluntary vowel imitation task and a lower, albeit significant, phonetic convergence effect in the vowel production 


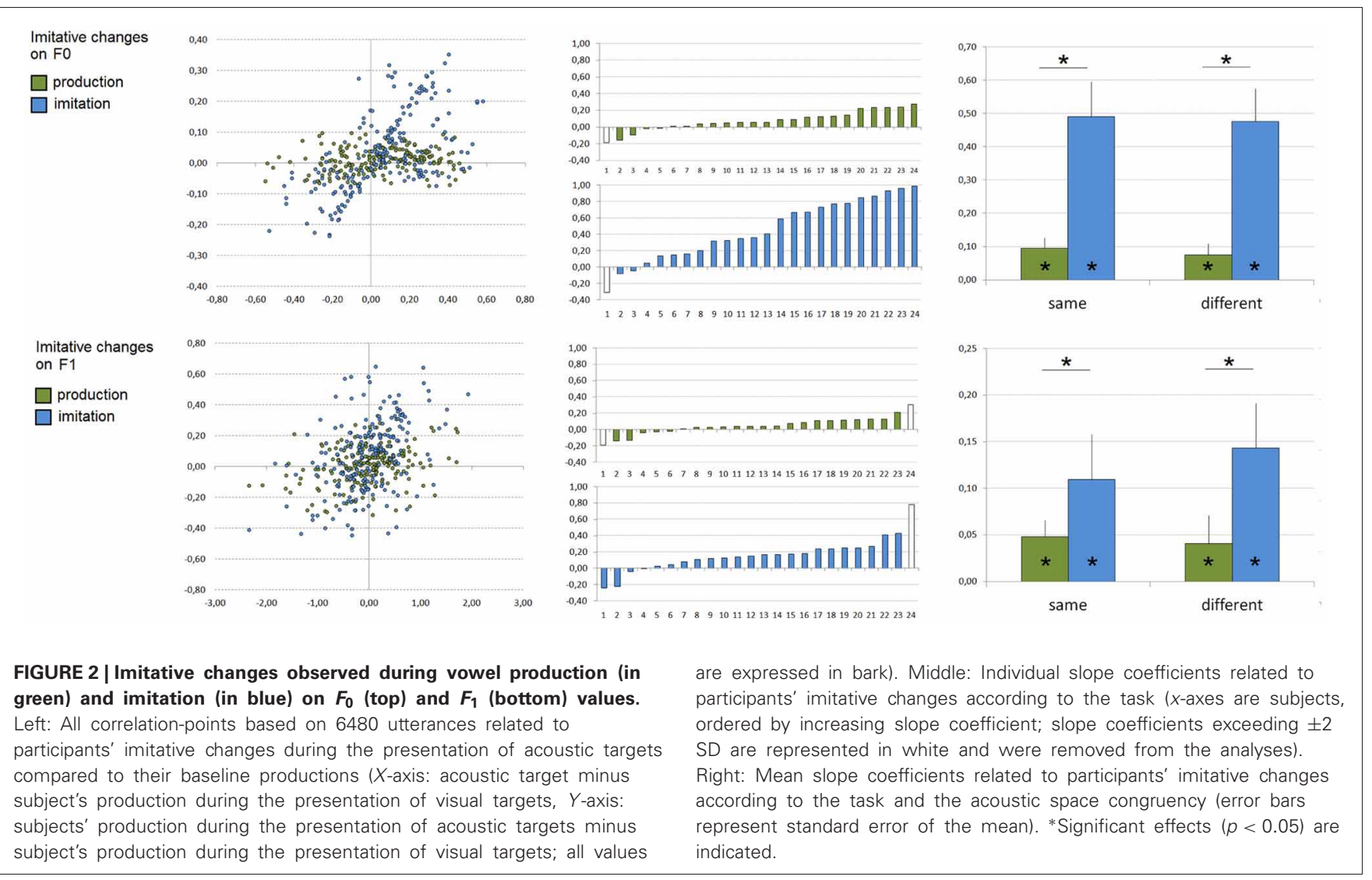

task. Interestingly, these effects were observed independently of the participant and speaker acoustic space congruency. Finally, it is worthwhile noting the large variability across participants, especially in the production task.

\section{AFTER-EFFECTS (PRODUCTION, IMITATION AND CATEGORIZATION EXPERIMENTS, SEE FIGURE 3)}

We also tested possible perceptuo-motor recalibration, i.e., aftereffects, compared to the participant's baseline. For each participant, block and vowel, median $F_{0}$ and $F_{1}$ values produced during the preceding baseline were subtracted from those produced during the second presentation of the orthographic targets. As previously, for each participant, one set of 9 correlation-points (from 3 blocks and 3 vowels) were therefore calculated for both $F_{0}$ and $F_{1}$ (see Figure 3 ) and single subject slope coefficients were estimated from these values by means of linear regressions. Slope coefficients exceeding $\pm 2 \mathrm{SD}$ were removed from the following analyses (corresponding to one, two and two participants in the production, imitation, and categorization experiments, respectively, for $F_{0}$, and two participants in the production, imitation, and categorization experiments for $F_{1}$, see Figure 3 ).

For both $F_{0}$ and $F_{1}$ slope coefficients, the remaining data were entered into ANOVA with the experiment (phonetic convergence, imitation, and auditory categorization) and the acoustic space congruency (same, different) as between-subject variables. In addition, individual one-tailed $t$-tests were performed for each experiment in order to test whether the mean slope coefficient was significantly superior to zero. As previously, in order to test whether after-effects on $F_{0}$ and $F_{1}$ may correlate, a Pearson's correlation analysis was performed between single subject slope coefficients on $F_{0}$ and $F_{1}$ for each experiment.

For $F_{0}$, ANOVA on single subject slope coefficients showed a significant effect of the task $\left[F_{(1,42)}=6.98, p<0.005\right]$, with stronger after-effects related to the acoustic targets after the imitation task compared to the production and categorization tasks (mean slope coefficients of $0.07,0.23$, and 0.07 in the production, imitation, and categorization experiments). No effect of the acoustic space congruency $\left[F_{(1,42)}=0.50\right]$ nor task $\times$ acousticspace congruency interaction $\left[F_{(1,42)}=0.49\right]$ were however observed. In addition, slope coefficients differed significantly from zero in both the production $\left[t_{(22)}=2.85, p<0.01\right]$, imitation $\left[t_{(22)}=4.92, p<0.001\right]$ and categorization $\left[t_{(21)}=3.44\right.$, $p<0.005]$ experiments.

For $\mathrm{F}_{1}$, no significant effect of the task $\left[F_{(1,41)}=0.08\right]$, of the acoustic space congruency $\left[F_{(1,41)}=0.11\right]$ nor interaction $\left[F_{(1,41)}=0.63\right]$ were observed. Slope coefficients differed significantly from zero in the production experiment [mean slope coefficient of $0.06 ; t_{(21)}=2.59, p<0.02$ ] but not in the imitation [mean slope coefficient of $0.04 ; t_{(21)}=1.83, p=0.07$ ] and categorization [mean slope coefficient of $0.04 ; t_{(21)}=1.88, p=0.07$ ] experiments.

In addition, Pearson's correlation analyses showed no significant correlation between single subject slope coefficients observed for after-effects on $F_{0}$ and $F_{1}$ in both the production $(r=-0.08$, slope $=-0.07)$, imitation $(r=0.10$, slope $=0.06)$ and categorization $(r=0.11$, slope $=0.18)$ experiments. 


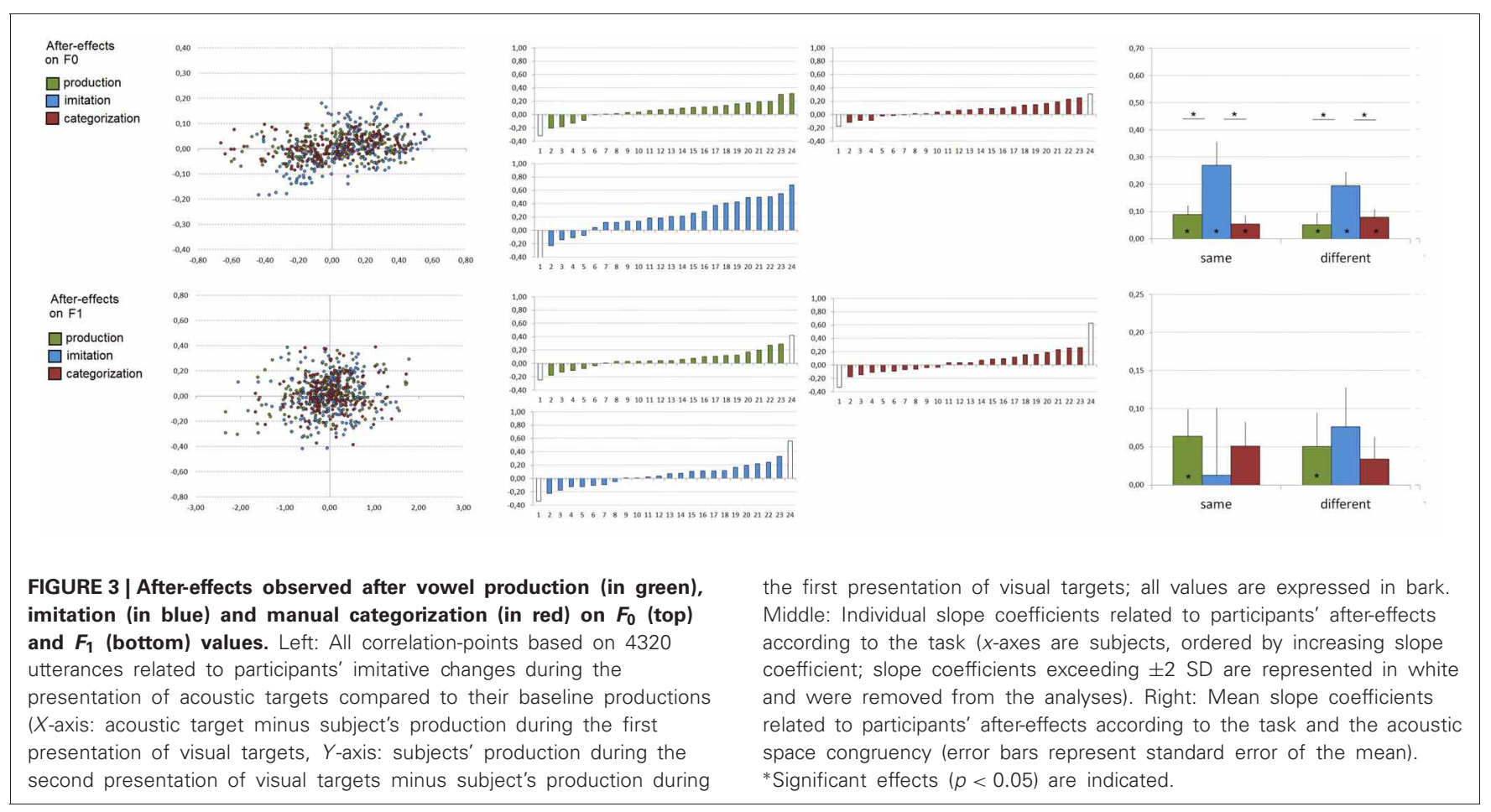

Hence, for $F_{0}$, offline perceptuo-motor recalibration processes were observed after vowel production, imitation, and categorization of the acoustic targets, with a stronger aftereffect after voluntary vowel imitation and lower, albeit significant, after-effects after vowel production and categorization. Furthermore, these effects were observed independently of the participant and speaker acoustic space congruency. For $F_{1}$, a small after-effect was only observed after vowel production, although there was also a trend in the same direction after vowel imitation and categorization. Finally, as for online adaptive changes, there was a large variability across participants in all tasks.

\section{RELATIONSHIPS BETWEEN IMITATIVE CHANGES AND AFTER-EFFECTS (PRODUCTION AND IMITATION EXPERIMENTS, SEE FIGURE 4)}

In order to test whether imitative changes and after-effects in the production and imitation experiments may correlate, Pearson's correlation analyses were performed for both $F_{0}$ and $F_{1}$ between single subject slope coefficients corresponding to the imitative changes and to the after-effects (see Figure 4). As previously, slope coefficients exceeding $\pm 2 \mathrm{SD}$ were removed from the analyses (corresponding to two participants in both experiments for $F_{0}$, and four and two participants in the production and imitation experiments for $F_{1}$, see Figure 4).

For $F_{0}$, the Pearson's correlation analysis showed a significant correlation between single subject slope coefficients observed for imitative changes and for after-effects in both the production $(r=$ 0.64 , slope $=0.71, p<0.005)$ and imitation $(r=0.78$, slope $=$ $0.52, p<0.001)$ experiments.

For $F_{1}$, the Pearson's correlation analysis also showed a significant correlation between single subject slope coefficients observed for imitative changes and for after-effects in the production experiment $(r=0.53$, slope $=0.85, p<0.03)$ but not in the imitation experiment $(r=0.31$, slope $=0.27)$.

\section{RELATIONSHIPS BETWEEN PHONETIC CONVERGENCE AND VOLUNTARY IMITATION (PRODUCTION AND IMITATION EXPERIMENTS)}

In order to test whether phonetic convergence and voluntary imitation in the production and imitation experiments may correlate for the subgroup of subjects who participated in both experiments, Pearson's correlation analyses were performed for both $F_{0}$ and $F_{1}$ between single subject slope coefficients corresponding to the convergence and imitative changes in the two experiments (see Figure 4). As previously, slope coefficients exceeding \pm 2 SD were removed from the analyses (corresponding to two participants for $F_{0}$, and one for $F_{1}$, see Figure 4).

The Pearson's correlation analysis showed no significant correlation between single subject slope coefficients observed for imitative changes in the two experiments for $F_{0}(r=-0.24$, slope $=-0.55)$ and $F_{1}(r=0.19$, slope $=0.38)$.

\section{DISCUSSION}

Influential models of speech motor control postulate a key role for on-line auditory and somatosensory feedback control mechanisms in speech production and highlight the sensorymotor nature of speech representations. However, studies on phonetic convergence suggest that speech production relies not only on phonemic sensory goals and actual sensory feedback but also on the processing of external speech inputs. In line with these findings, the present study demonstrates, in a noninteractive situation of communication, both unintentional and voluntary imitative changes in fundamental and first formant 


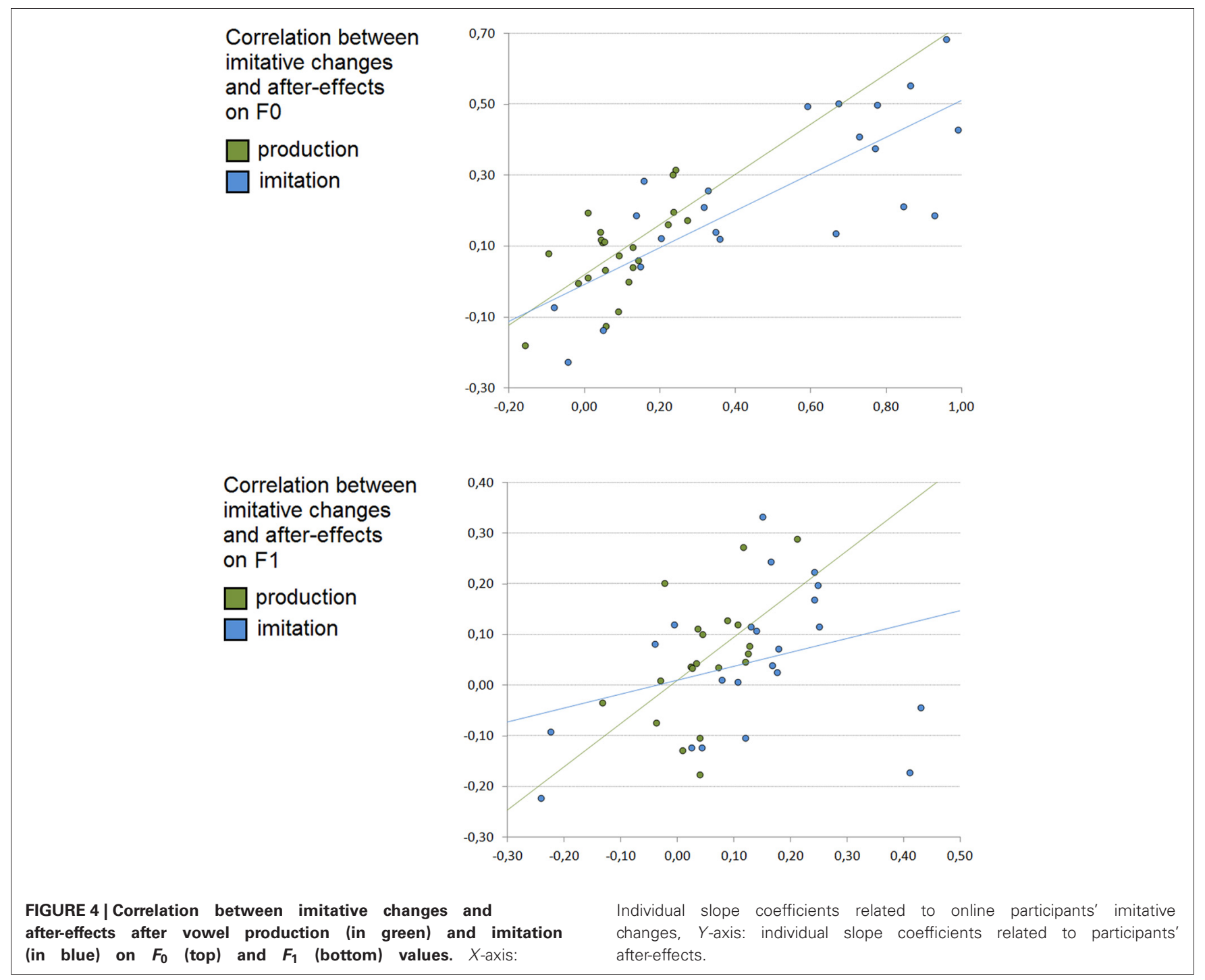

frequencies of acoustic vowel targets during speech production and imitation tasks. Offline perceptuo-motor recalibration processes on fundamental frequency - and possibly, marginally, for first formant frequency-were also observed after vowel production, imitation, and categorization of the acoustic targets. In addition, while a significant correlation was observed between imitative changes and after-effects in both vowel production and imitation tasks, no correlation occurred between phonetic convergence effects and voluntary imitative changes for the subgroup of subjects who participated in both experiments on vowel production and imitation. Altogether, these results demonstrate adaptive plasticity of phonemic sensory-motor goals and suggest that speech production draws on both sensorymotor knowledge and perceptual learning of the external speech environment.

\section{ONLINE UNINTENTIONAL AND VOLUNTARY IMITATIVE CHANGES}

Phonetic convergence effects have been initially explored during natural and interactive settings, notably during conversational exchanges between two speaking partners (Pardo, 2006; Aubanel and Nguyen, 2010; Pardo et al., 2010; Kim et al., 2011; Lelong and Bailly, 2011). This led to the hypothesis that "speech accommodation" may facilitate conversational exchange by contributing to setting a common ground between speakers (Giles et al., 1991; see also Garrod and Pickering, 2004; Pickering and Garrod, 2004, 2007). However, other studies conducted in a non-interactive laboratory setting, as when hearing and/or seeing a recorded speaker influences the production of similar or dissimilar speech sounds (Goldinger and Azuma, 2004; Gentilucci and Cattaneo, 2005; Delvaux and Soquet, 2007; Gentilucci and Bernardis, 2007; Kappes et al., 2009; Babel and Bulatov, 2012), indicate that convergence mechanisms do not depend on mutual adjustments and social attunement only. In our view, these later studies provide powerful evidence that, unless hindered by higher-order sociopsychological factors, phonetic convergence is a highly automatized process (for a review, see Delvaux and Soquet, 2007) that may also be triggered by low-level sensory and motor adaptive processes. 
Based on $F_{0}$ and $F_{1}$ acoustic analyses of a large corpus of recorded vowels, the present study replicates and extends phonetic convergence effects previously observed on fundamental frequency (Gregory, 1986; Gregory et al., 1993; Bosshardt et al., 1997; Kappes et al., 2009; Babel and Bulatov, 2012) and on formant frequencies and spectral distributions (Gentilucci and Cattaneo, 2005; Delvaux and Soquet, 2007; Gentilucci and Bernardis, 2007; Aubanel and Nguyen, 2010; Lelong and Bailly, 2011). First, online imitative changes on both $F_{0}$ and $F_{1}$ in relation to the acoustic vowel targets were observed in a noninteractive situation of communication during the production task, with none of the participants reporting having voluntarily imitated the acoustic stimuli. Second, although previous studies usually involved the production of words or sentences (Goldinger, 1998; Goldinger and Azuma, 2004; Pardo, 2006; Delvaux and Soquet, 2007; Kappes et al., 2009; Aubanel and Nguyen, 2010; Pardo et al., 2010; Kim et al., 2011; Lelong and Bailly, 2011; Babel and Bulatov, 2012), adaptive changes were here observed during vowel production thus minimizing lexical/semantic processing (for phonetic convergence effects on $F_{0}$ and/or $F_{1}$ during syllable or non-word production, see Gentilucci and Cattaneo, 2005; Gentilucci and Bernardis, 2007; Kappes et al., 2009). Altogether, these findings thus suggest that phonetic convergence may also derive from unintentional and automatic adaptive sensory-motor speech mechanisms. However, it is worthwhile noting that, although significant at the group level, the magnitude of these adaptive changes was rather small (mean slope coefficients of 0.08 and of 0.04 for $F_{0}$ and $F_{1}$, respectively) and quite variable across participants (individual slope coefficients ranging from -0.16 to 0.27 and from -0.14 to 0.21 for $F_{0}$ and $F_{1}$, respectively). In addition, although phonetic convergence was attested for both $F_{0}$ and $F_{1}$, adaptive changes were twice lower for $F_{1}$. In the experiments, however, $F_{0}$ values of the vowel targets remained similar within each block while $F_{1}$ varied according to each vowel type. Although sensory-motor and convergence mechanisms are likely to differ for these acoustic parameters at the acoustical, biomechanical and neurobiological levels, it appears difficult to speculate on these observed differences. Finally, although gender effects have been previously observed on phonetic convergence (Pardo, 2006; Pardo et al., 2010; Babel and Bulatov, 2012), the exact nature of this mediation remains unclear and may depend on both specific experimental designs and/or "macro" social mechanisms, out of the scope of this study. Given the limited number of participants in each sub-experimental group condition (i.e., six female and six male participants presented with acoustic targets from the female speakers, and six female and six male participants presented with acoustic targets from the male speakers), we rather focused on the participant and speaker acoustic space congruency. Phonetic convergence was observed independently of the participant and speaker acoustic space congruency, a result suggesting that phonetic convergence on vowels and in a non-interactive situation of communication is pervasive and not strongly influenced by the acoustic distance between the participant and the model speaker.

To compare phonetic convergence and voluntary imitation of the acoustic vowels, a second group of participants performed the same experiment except that they were explicitly asked to imitate the acoustic targets. As expected, stronger online imitative changes according to the acoustic vowel targets were observed during voluntary imitation (mean slope coefficients of 0.48 vs. 0.08 for $F_{0}$ and 0.13 vs. 0.04 for $F_{1}$, for the imitation and production tasks, respectively). As in the production tasks, imitative changes were however quite variable across participants (individual slope coefficients ranging from -0.8 to 0.99 and from -0.24 to 0.43 for $F_{0}$ and $F_{1}$, respectively). In addition, no significant correlation between phonetic convergence and voluntary imitation on both $F_{0}$ and $F_{1}$ were observed for the subgroup of subjects who participated in both the production and imitation task. Interestingly, although not significant, the slope coefficient for $F_{0}$ appears nevertheless quite high (mean slope coefficients of -0.55). Hence, although this last result does not indicate any significant correlation, possible dependencies between phonetic convergence and voluntary imitation have to be further investigated in future studies.

\section{PERCEPTUO-MOTOR RECALIBRATION PROCESSES}

Interestingly, previous studies showed clear evidence of postexposure imitation, with experimental designs and long-lasting effects that preclude strategic explanations (Goldinger and Azuma, 2004; Pardo, 2006; Delvaux and Soquet, 2007). In these studies, phonetic convergence was first attested during the production of auditorily presented words in a non-interactive situation of communication. Offline adaptation to the acoustic targets was however observed in post-tests occurring either immediately (Pardo, 2006; Delvaux and Soquet, 2007) or even conducted one week after the production task (Goldinger and Azuma, 2004; see also Goldinger, 1998 using a close-shadowing task). These latter findings suggest that long-term memory to some extent preserves detailed traces of the auditorily presented words and thus support episodic/exemplar theories of word processing assuming that paralinguistic details of a spoken word are stored together as a memory trace (e.g., Nygaard et al., 1994; Goldinger, 1996, 1998; Nygaard and Pisoni, 1998), although hybrid models combining abstract phonological representations with episodic memory traces are also consistent with these results (e.g., McQueen et al., 2006; Pierrehumbert, 2006). Importantly, Pardo (2006) and Delvaux and Soquet (2007) also propose that these observed phonetic convergence and associated long-term adaptive changes may be at the source of gradual diachronic changes of a phonological system in a community.

In line with these studies, offline perceptuo-motor recalibration processes were here observed for $F_{0}$ after vowel production, imitation and auditory categorization of the acoustic targets, with a stronger after-effect observed after voluntary vowel imitation. The fact that after-effects equally occurred following prior vowel production and perceptual categorization of the acoustic targets likely suggests that these effects rely on perceptual processing and learning from the acoustic targets, without the need for a specific motor learning stage. As for online imitative changes, these effects were observed independently of the participant and speaker acoustic space congruency and, although significant at the group level, the magnitude of these after-effects was rather small (mean slope coefficients of $0.07,0.23$, and 0.07 for the production, imitation and categorization tasks, respectively) and quite variable across participants (individual slope coefficients 
ranging from -0.20 to 0.32 , from -0.23 to 0.68 and from -0.12 to 0.25 for the production, imitation and categorization tasks, respectively). As expected, a significant correlation between single subject slope coefficients for imitative changes and after-effects was also observed in both the production and imitation tasks.

For $F_{1}$, a small after-effect was only observed after vowel production (although there was a trend after vowel imitation and categorization), with a significant correlation between single subject slope coefficients for imitative changes and after-effects. The after-effect for $F_{1}$ in the production task and the trend found in the imitation and categorization tasks were therefore observed despite $F_{1}$ values of the acoustic targets varying according to each vowel type in each block. Finally, it is also interesting to note that for $F_{1}$ the imitation task did not provide stronger after-effects as compared to the other tasks. More intriguing is the very low aftereffect observed in the imitation tasks when subjects and targets were of the same gender, a phenomenon for which we do have no clear explanation yet.

\section{PERCEPTUO-MOTOR LEARNING AND INTERNAL MODELS OF SPEECH PRODUCTION}

Altogether, our results demonstrate adaptive plasticity of phonemic sensory-motor goals in a non-interactive situation of communication, without lexical/semantic processing of the acoustic targets. Although they appear in line with previous studies on phonetic convergence and do not contradict the theoretical proposal that adaptive changes in speech production facilitate conversational exchanges between speaking partners, these results demonstrate that, in addition to social attunement and lexi$\mathrm{cal} /$ semantic processing, convergence effects may also be triggered by low-level sensory and motor adaptive speech processes. From that point of view, future studies on phonetic convergence contrasting interactive and non-interactive laboratory settings will be of great interest to further determine whether social interactions might enhance imitative changes.

Together with previous studies on phonetic convergence and imitation, the observed adaptive plasticity of phonemic sensorymotor goals sheds an important light on speech motor control and internal models of speech production (for reviews, Perkell et al., 1997, 2000; Perrier, 2005, 2012; Guenther, 2006; Guenther and Vladusich, 2012; Perkell, 2012). As previously noted, these models postulate that auditory and somatosensory systems play a key role in speech motor control and that speech goals are defined in multi-dimensional motor, auditory, and somatosensory spaces. However, they mainly focus on the flexibility of motor processes, without regard for possible adaptive changes of phonemic sensory representations that are presumed to constitute the sensory goals of speech movements. Convergence and perceptuo-motor recalibration processes however demonstrate that speech production relies not only on the intended phonemic sensory goals and actual sensory feedback but also on the processing of external speech inputs. In our view, these effects are based on complex sensorimotor interactions, allowing the speaker to compare or tune his/her own sensory and motor speech repertoire with the phonetic characteristics of the perceived utterance, and leading to perceptuo-motor learning from the external speech environment. During speech production, phonetic convergence and after-effects may therefore arise from induced plasticity of phonemic sensory and motor representations, in relation to relevant adjustment of motor commands. Convergence effects are thus of considerable interest since they suggest that speech motor goals are continuously updated in response to changes in the sensory and linguistic aspects of speech inputs. Hence, as also advocated by Perkell (2012), adaptive processes, likely to modify online, to a certain extent, sensory speech representations, will have to be taken into account in future versions of speech motor control models.

From that view, there is now considerable neurobiological evidence that sensorimotor interactions play a key role in both speech perception and speech production. In line with internal models of speech production, modulation of neural responses observed within the auditory and somatosensory cortices when speaking are thought to reflect feedback control mechanisms in which predicted sensory consequences of the speech-motor act are compared with actual sensory input in order to further control production (Guenther, 2006; Tian and Poeppel, 2010; Hickok et al., 2011; Houde and Nagarajan, 2011; Price et al., 2011; Guenther and Vladusich, 2012; Hickok, 2012). In addition, it has been suggested that motor activity during speech perception partly constrains phonetic interpretation of the sensory inputs through the internal generation of candidate articulatory categories (Callan et al., 2004; Wilson and Iacoboni, 2006; Skipper et al., 2007; Poeppel et al., 2008; Rauschecker and Scott, 2009; Hickok et al., 2011; Rauschecker, 2011). From these models, perceptuo-motor learning and plasticity of phonemic goals induced by convergence and sensory-motor adaptive processes might depend on both a ventral and dorsal stream (Guenther, 2006; Hickok and Poeppel, 2007; Rauschecker and Scott, 2009; Hickok et al., 2011; Rauschecker, 2011; Guenther and Vladusich, 2012; Hickok, 2012; see also Grabski et al., 2013 for recent brainimaging evidence that vowel production and perception both rely on these dorsal and ventral streams). The ventral stream ("what") is supposed to be in charge for phonological and lexical processing, and thought to be localized in the anterior part of the superior temporal gyrus/sulcus (Scott and Johnsrude, 2003; Rauschecker and Scott, 2009; Rauschecker, 2011) or in the posterior part of the middle temporal gyrus and superior temporal sulcus (Hickok and Poeppel, 2007). The dorsal stream ("how") would deal with sensory-motor mapping between sensory speech representations in the auditory temporal and somatosensory parietal cortices and articulatory representations in the ventral premotor cortex and the posterior part of the inferior frontal gyrus, with sensorimotor interaction converging in the supramarginal gyrus (Rauschecker and Scott, 2009; Rauschecker, 2011) or in area SPT (a brain region within the planum temporale near the parieto-temporal junction; Hickok and Poeppel, 2007). In line with the involvement of both the dorsal and ventral streams in imitative changes in speech production, recent studies using repetition, shadowing or voluntary imitation tasks have provided evidence for a neuro-functional/neuro-anatomical signature of speech imitation ability, mostly relying on the superior temporal gyrus, the premotor cortex and the inferior parietal lobule (Peschke et al., 2009; Irwin et al., 2011; Reiterer et al., 2011; Mashal et al., 2012). From these findings, the neural basis of 
low-level sensory and motor adaptive speech processes involved in phonetic convergence and perceptuo-motor recalibration processes remains to be investigated in future studies.

\section{ACKNOWLEDGMENTS}

This study was supported by research grants from the Centre National de la Recherche Scientifique (CNRS) and the Agence

\section{REFERENCES}

Abbs, J. H., and Gracco, V. L. (1984). Control of complex motor gestures: orofacial muscle responses to load perturbations of lip during speech. J. Neurophysiol. 51, 705-723.

Aubanel, V. (2011). Variation Phonologique Régionale en Interaction Conversationnelle. Doctoral Dissertation, Aix-Marseille University.

Aubanel, V., and Nguyen, N. (2010). Automatic recognition of regional phonological variation in conversational interaction. Speech Commun. 52, 577-586. doi: 10.1016/j.specom.2010.02.008

Babel, M. (2009). Phonetic and Social Selectivity in Speech Accommodation. Doctoral Dissertation, University of California, Berkeley.

Babel, M., and Bulatov, D. (2012). The role of fundamental frequency in phonetic accommodation. Lang. Speech 55, 231-248. doi: $10.1177 / 0023830911417695$

Bertelson, P., Vroomen, J., and De Gelder, B. (2003). Visual recalibration of auditory speech identification: a mcgurk aftereffect. Psychol. Sci. 14, 592-597. doi: 10.1046/j.09567976.2003.psci_1470.x

Boersma, P., and Weenink, D. (2013). Praat: Doing Phonetics by Computer [Computer program]. Version 5.3.42. Available online at: http://www.praat.org/ (Accessed 2 March, 2013).

Bosshardt, H. G., Sappok, C., Knipschild, M., and Hölscher, C. (1997). Spontaneous imitation of fundamental frequency and speech rate by nonstutterers and stutterers. J. Psycholinguist. Res. 26, 425-448. doi: 10.1023/A:1025030120016

Bradlow, A. R., and Bent, T. (2008). Perceptual adaptation to non-native speech. Cognition 106, 707-729. doi: 10.1016/j.cognition.2007.04.005

Burnett, T. A., Freedland, M. B., Larson, C. R., and Hain, T. C. (1998). Voice F0 responses to manipulations in pitch feedback. J. Acoust. Soc. Am. 103, 3153-3161. doi: $10.1121 / 1.423073$
Cai, S., Ghosh, S. S., Guenther, F. manipulations of formant trajectories reveal a role of auditory feedback in the online control of both within-syllable and between-syllable speech timing. J. Neurosci. 31, 16483-16490. doi: 10.1523/JNEUROSCI.3653-11.2011

Callan, D. E., Jones, J. A., Callan, A. M., and Akahane-Yamada, R. (2004). Phonetic perceptual identification by native- and secondlanguage speakers differentially activates brain regions involved with acoustic phonetic processing and those involved with articulatoryauditory/orosensory internal models. Neuroimage 22, 1182-1194. doi: 10.1016/j.neuroimage.2004.03.006

Clarke, C. M., and Garrett, M. F. (2004). Rapid adaptation to foreign accented English. J. Acoust. Soc. Am. 116, 3647-3658. doi: $10.1121 / 1.1815131$

Delvaux, V., and Soquet, A. (2007). The influence of ambient speech on adult speech productions through unintentional imitation. Phonetica 64, 145-173. doi: 10.1159/000107914

Elman, J. L. (1981). Effects of frequency- shifted feedback on the pitch of vocal productions. J. Acoust. Soc. Am. 70, 45-50. doi: $10.1121 / 1.386580$

Estow, S., Jamieson, J. P., and Yates, J. R. (2007). Self-monitoring and mimicry of positive and negative social behaviors. J. Res. Pers. 41, 425-433. doi: 10.1016/j.jrp.2006.05.003

Feng, Y., Gracco, V. L., and Max, L. (2011). Integration of auditory and somatosensory error signals in the neural control of speech movements. J. Neurophysiol. 106, 667-679. doi: 10.1152/jn.00638.2010

Flege, J. E. (1987). The production of "new" and "similar" phones in a foreign language: Evidence for the effect of equivalence classification. J. Phon. 15, 47-65.

Flege, J. E., and Eefting, W. (1987). Cross-language switching in stop consonant perception and production by Dutch speakers of English. H., and Perkell, J. S. (2011). Focal

Nationale de la Recherche (ANR SPIM-Imitation in speech: from sensori-motor integration to the dynamics of conversational interaction). Any opinions, findings, and conclusions or recommendations expressed in this material are those of the authors and do not necessarily reflect the views of the funding agencies. We thank Pascal Perrier for helpful discussions on internal models of speech motor control.

Speech Commun. 6, 185-202. doi: 10.1016/0167-6393(87)90025-2

Folkins, J. W., and Abbs, J. H. (1975). Lip and jaw motor control during speech: responses to resistive loading of the jaw. J. Speech Hear. Res. 18, 207-219.

Fowler, C. (1986). An event approach to the study of speech perception from a direct-realist perspective. J. Phon. 14, 3-28.

Fowler, C. A., Sramko, V., Ostry, D. J. Rowland, S. A., and Halle, P. (2008). Cross language phonetic influences on the speech of French-English bilinguals. J. Phon. 36, 649-663. doi: 10.1016/j.wocn.2008.04.001

Francis, B. A., and Wonham, W. M. (1976). The internal model principle of control theory. Automatica 12, 457-651. doi: 10.1016/00051098(76)90006-6

Galantucci, B., Fowler, C. A., and Turvey, M. T. (2006). The motor theory of speech perception reviewed. Psychon. Bull. Rev. 13, 361-377. doi: 10.3758/BF03193857

Garrod, S., and Pickering, M. J. (2004) Why is conversation so easy? Trends Cogn. Sci. 8, 8-11. doi: 10.1016/j.tics.2003.10.016

Gentilucci, M., and Bernardis, P. (2007). Imitation during phoneme production. Neuropsychologia 45, 608-615. doi: 10.1016/ j.neuropsychologia.2006.04.004

Gentilucci, M., and Cattaneo, L. (2005). Automatic audiovisual integration in speech perception. Exp. Brain Res. 167, 66-75. doi: 10.1007/s00221005-0008-z

Giles, H., Coupland, N., Coupland, J. (1991). "Accommodation theory: communication, context, and consequence," in Contexts of Accommodation: Developments in Applied Sociolinguistics, eds H. Giles, N. Coupland, and J. Coupland (Cambridge, UK: Cambridge University Press), 1-68. doi: $\quad 10.1017 / \mathrm{CBO} 9780511663$ 673.001

Goldinger, S. D. (1996). Words and voices: episodic traces in spoken word identification and recognition memory. J. Exp. Psychol. Learn. Mem. Cogn. 22, 1166-1183. doi: 10.1037/0278-7393.22.5.1166
Goldinger, S. D. (1998). Echoes of echoes? An episodic theory of lexical access. Psychol. Rev. 105, 251-279. doi: 10.1037/0033-295X.105.2.251

Goldinger, S. D., and Azuma, T. (2004). Episodic memory reflected in printed word naming. Psychon. Bull. Rev. 11, 716-722. doi: 10.3758/BF03196625

Grabski, K., Schwartz, J. L., Lamalle, L., Vilain, C., Vallée, N., Baciu, M., et al. (2013). Shared and distinct neural correlates of vowel perception and production. J. Neurolinguist. 26, 384-408. doi: 10.1016/j.jneuroling.2012.11.003

Gracco, V. L., and Abbs, J. H. (1985). Dynamic control of the perioral system during speech: kinematic analyses of autogenic and nonautogenic sensorimotor processes. J. Neurophysiol. 54, 418-432.

Gregory, S. W. (1986). Social psychological implications of voice frequency correlations: analyzing conversation partner adaptation by computer. Soc. Psychol. Q. 49, 237-246. doi: 10.2307/ 2786806

Gregory, S. W., Webster, S., and Huang, G. (1993). Voice pitch and amplitude convergence as a metric of quality in dyadic interviews. Lang. Commun. 13, 195-217. doi: 10.1016/0271-5309(93)90026-J

Guenther, F. H. (1995). Speech sound acquisition, coarticulation, and rate effects in a neural network model of speech production. Psychol. Rev. 102, 594-621. doi: 10.1037/0033295X.102.3.594

Guenther, F. H. (2006). Cortical interactions underlying the production of speech sounds. J. Commun. Disord. 39, 350-365. doi: 10.1016/j.jcomdis.2006.06.013

Guenther, F. H., Hampson, M., and Johnson, D. (1998). A theoretical investigation of reference frames for the planning of speech movements. Psychol. Rev. 105, 611-633. doi: 10.1037/0033-295X.105.4.611-633

Guenther, F. H., and Vladusich, T. (2012). A neural theory of speech acquisition and production. J. Neurolinguist. 25, 408-422. doi: 10.1016/j.jneuroling.2009.08.006 
Hickok, G. (2012). Computational neuroanatomy of speech production. Nat. Rev. Neurosci. 13, 135-145.

Hickok, G., Houde, J., and Rong, F. (2011). Sensorimotor integration in speech processing: computational basis and neural organization. Neuron 69, 407-422. doi: 10.1016/j.neuron.2011.01.019

Hickok, G., and Poeppel, D. (2007). The cortical organization of speech processing. Nat. Rev. Neurosci. 8, 393-402. doi: 10.1038/nrn2113

Houde, J. F., and Jordan, M. I. (1998). Sensorimotor adaptation in speech production. Science 279, 1213-1216. doi: 10.1126/science.279.5354.1213

Houde, J. F., and Nagarajan, S. S. (2011). Speech production as state feedback control. Front. Hum. Neurosci. 5:82. doi: 10.3389/fnhum.2011.00082

Houde, J. F., Nagarajan, S. S., Sekihara, K., and Merzenich, M. M. (2002). Modulation of the auditory cortex during speech: an MEG study. J. Cogn. Neurosci. 14, 1125-1138. doi: $10.1162 / 089892902760807140$

Irwin, J. R., Frost, S. J., Menci, W. E., Chen, H., and Fowler, C. A. (2011). Functional activation for imitation of seen and heard speech. J. Neurolinguist. 24, 611-618. doi: 10.1016/j.jneuroling.2011.05.001

Jones, J. A., and Munhall, K. G. (2000). Perceptual calibration of F0 production: evidence from feedback perturbation. J. Acoust. Soc. Am. 108, 1246-1251. doi: 10.1121/1.1288414

Kappes, J., Baumgaertner, A., Peschke, C., and Ziegler, W. (2009). Unintended imitation in nonword repetition. Brain Lang. 111, 140-151. doi: 10.1016/j.bandl.2009.08.008

Kawato, M., Furukawa, K., and Suzuki, R. (1987). A hierarchical neural network model for the control and learning of voluntary movements. Biol. Cybern. 56, 1-17.

Kim, M., Horton, W. S., and Bradlow, A. R. (2011). Phonetic convergence in spontaneous conversations as a function of interlocutor language distance. Lab. Phonol. 2, 125-156. doi: 10.1515/labphon.2011.004

Kraljic, T., and Samuel, A. G. (2005). Perceptual learning for speech: is there a return to normal? Cogn. Psychol. 51, 141-178. doi: 10.1016/j.cogpsych.2005.05.001

Kraljic, T., and Samuel, A. G. (2006). Generalization in perceptual learning for speech. Psychon. Bull. Rev. 13, 262-268. doi: 10.3758/BF03193841

Kraljic, T., and Samuel, A. G. (2007). Perceptual adjustments to multiple speakers. J. Mem. Lang. 56, 1-15. doi: 10.1016/j.jml.2006.07.010

Kuhl, P. K. (2004). Early language acquisition: cracking the speech code. Nat. Rev. Neurosci. 5, 831-843. doi: 10.1038/nrn1533

Kuhl, P. K., Andruski, J. E., Chistovich, I. A., Chistovich, L. A., Kozhevnikova, E. V., Ryskina, V. L., et al. (1997). Cross-language analysis of phonetic units in language addressed to infants. Science 277, 684-686. doi: 10.1126/science.277.5326.684

Kuhl, P. K., and Meltzoff, A. N. (1996). Infant vocalizations in response to speech: vocal imitation and developmental change. J. Acoust. Soc. Am. 100, 2425-2438. doi: $10.1121 / 1.417951$

Ladefoged, P., and Broadbent, D. E. (1957). Information conveyed by vowels. J. Acoust. Soc. Am. 29, 98-104. doi: 10.1121/1.1908694

Lametti, D. R., Nasir, S., and Ostry, D. J. (2012). Sensory preference in speech production revealed by simultaneous alteration of auditory and somatosensory feedback. J. Neurosci. 32, 9351-9359. doi: 10.1523/JNEUROSCI.0404-12.2012

Lelong, A. (2012). Convergence Phonétique en Interaction. Doctoral Dissertation, Grenoble University.

Lelong, A., and Bailly, G. (2011). "Study of the phenomenon of phonetic convergence thanks to speech dominoes," in Analysis of Verbal and Nonverbal Communication and Enactment: the Processing Issue, eds A. Esposito, A. Vinciarelli, K. Vicsi, C. Pelachaud, and A. Nijholt (Grenoble: Springer Verlag), 280-293.

Liberman, A. M., Cooper, F. S., Shankweiler, D. P., and StuddertKennedy, M. (1967). Perception of the speech code. Psychol. Rev. 74, 431-461. doi: 10.1037/h0020279

Liberman, A. M., and Mattingly, I. G. (1985). The motor theory of speech perception revised. Cognition 21, 1-36. doi: 10.1016/0010-0277(85)90021-6

Liberman, A. M., and Whalen, D. H. (2000). On the relation of speech to language. Trends Cogn. Sci. 3, 254-264.

Mann, V. A., and Repp, B. H. (1980). Influence of vocalic context on perception of the [zh]-[s] distinction. Percept. Psychophys. 28, 213-228. doi: 10.3758/BF03204377

Mashal, N., Solodkin, A., Dick, A. S., Chen, E. E., and Smal, S. L. (2012). A network model of observation and imitation of speech? Front. Psychol. 3:84. doi: 10.3389/fpsyg.2012.00084
McQueen, J. M., Norris, D., and Cutler, A. (2006). The dynamic nature of speech perception. Lang. Speech 49, 101-112. doi: 10.1177/00238309060490010601

Ménard, L., Schwartz, J. L., and Aubin, J. (2008). Invariance and variability in the production of the height feature in french vowels. Speech Commun. 50, 14-28. doi: 10.1016/j.specom.2007.06.004

Ménard, L., Schwartz, J. L., Boë, L. J., Kandel, S., and Vallée, N. (2002). Auditory normalization: of French vowels synthesized by an articulatory model simulating growth from birth to adulthood. J. Acoust. Soc. Am. 111, 1892-1905. doi: $10.1121 / 1.1459467$

Miller, J. L., and Liberman, A. M. (1979). Some effects of lateroccurring information on the perception of stop consonant and semivowel. Percept. Psychophys. 25, 457-465. doi: 10.3758/BF03213823

Nasir, S. M., and Ostry, D. J. (2006). Somatosensory precision in speech production. Curr. Biol. 16, 1918-1923. doi: 10.1016/j.cub.2006.07.069

Nasir, S. M., and Ostry, D. J. (2009). Auditory plasticity and speech motor learning. Proc. Natl. Acad. Sci. U.S.A. 106, 20470-20475. doi: 10.1073/pnas.0907032106

Natale, M. (1975). Convergence of mean vocal intensity in dyadic communication as a function of social desirability. J. Pers. Soc. Psychol. 32, 790-804. doi: 10.1037/00223514.32.5.790

Norris, D., McQueen, J. M., and Cutler, A. (2003). Perceptual learning in speech. Cogn. Psychol. 47, 204-238. doi: 10.1016/S0010-0285(03)000069

Nygaard, L. C., and Pisoni, D. B. (1998). Talker-specific learning in speech perception. Percept. Psychophys. 60 355-376. doi: 10.3758/BF03206860

Nygaard, L. C., Sommers, M. S., and Pisoni, D. B. (1994). Speech perception as a talker contingent process. Psychol. Sci. 5, 42-45. doi: 10.1111/j.14679280.1994.tb00612.x

Pardo, J. S. (2006). On phonetic convergence during conversational interaction. J. Acoust. Soc. Am. 119, 2382-2393. doi: 10.1121/1.2178720

Pardo, J. S., Jay, I. C., and Krauss, R. M. (2010). Conversationnal role influences speech imitation. Atten. Percept. Psychophys. 72, 2254-2264.

Perkell, J. S. (2012). Movement goals and feedback and feedforward control mechanisms in speech production.
J. Neurolinguist. 25, 382-407. doi: 10.1016/j.jneuroling.2010.02.011

Perkell, J. S., Guenther, F. H., Lane, H., Matthies, L. M., Perrier, P., Vick, J., et al. (2000). A theory of speech motor control and supporting data from speakers with normal hearing and with profound hearing loss. J. Phon. 28, 233-272. doi: 10.1006/jpho.2000.0116

Perkell, J. S., Matthies, M. L., Lane, H., Guenther, F. H., WilhelmsTricarico, R., Wozniak, J. et al. (1997). Speech motor control: acoustic goals, saturation effects, auditory feedback and internal models. Speech Commun. 22, 227-250. doi: 10.1016/S0167-6393(97)00026-5

Perrier, P. (2005). Control and representations in speech production. ZAS Papers Linguist. 40, 109-132.

Perrier, P. (2012). "Gesture planning integrating knowledge of the motor plant's dynamics: a literature review from motor control and speech motor control," in Speech Planning and Dynamics, eds S. Fuchs, M. Weirich, D. Pape, and P. Perrier (Frankfurt: Peter Lang), 191-238.

Peschke, C., Ziegler, W., Kappes, J., and Baumgaertner, A. (2009). Auditory-motor integration during fast repetition: the neuronal correlates of shadowing. Neuroimage 47, 392-402. doi: 10.1016/j.neuroimage.2009.03.061

Pickering, M. J., and Garrod, S. (2004). Towards a mechanistic psychology of dialogue. Behav. Brain Sci. 27, 169-190. doi: 10.1017/S0140525X04000056

Pickering, M. J., and Garrod, S. (2007). Do people use language production to make predictions during comprehension? Trends Cogn. Sci. 11, 105-110. doi: 10.1016/j.tics.2006.12.002

Pierrehumbert, J. (2006). The next toolkit. J. Phon. 34, 516-530. doi: 10.1016/j.wocn.2006.06.003

Poeppel, D., Idsardi, W. J., and van Wassenhove, V. (2008). Speech perception at the interface of neurobiology and linguistics. Philos. Trans. R. Soc. Lond. B Biol. Sci. 363, 1071-1086. doi: 10.1098/rstb.2007.2160

Porter, R. J., and Lubker, J. F. (1980). Rapid reproduction of vowel sequences: evidence for a fast and direct acoustic motoric linkage in speech. J. Speech Hear. Res. 23, 593-602.

Price, C. J., Crinion, J. T., and MacSweeney, M. (2011). A generative model of speech production in Broca's and Wernicke's 
areas. Front. Psychol. 2:237. doi: 10.3389/fpsyg.2011.00237

Purcell, D. W., and Munhall, K. G. (2006a) Compensation following real-time manipulation of formants in isolated vowels. J. Acoust. Soc. Am. 119, 2288-2297. doi: $10.1121 / 1.2173514$

Purcell, D. W., and Munhall, K. G. (2006b) Adaptive control of vowel formant frequency: evidence from real-time formant manipulation. J. Acoust. Soc. Am. 120, 966-977. doi: $10.1121 / 1.2217714$

Rauschecker, J. P. (2011). An expanded role for the dorsal auditory pathway in sensorimotor control and integration. Hear. Res. 271, 16-25. doi: 10.1016/j.heares.2010.09.001

Rauschecker, J. P., and Scott, S. K. (2009). Maps and streams in the auditory cortex: Nonhuman primates illuminate human speech processing. Nat. Neurosci. 12, 718-724. doi: 10.1038/nn.2331

Reiterer, S. M., Hu, X., Erb, M., Rota, G., Nardo, D., Grodd, W., et al. (2011). Individual differences in audio-vocal speech imitation aptitude in late bilinguals: functional neuro-imaging and brain morphology. Front. Psychol. 2:271. doi: 10.3389/fpsyg.2011.00271

Rochet-Capellan, A., and Ostry, D. J. (2011). Simultaneous acquisition of multiple auditorymotor transformations in speech. J. Neurosci. 31, 2657-2662. doi: 10.1523/ JNEUROSCI.6020-10.2011

Rochet-Capellan, A., and Ostry, D. J. (2012). Nonhomogeneous transfer reveals specificity in speech motor learning. J. Neurophysiol. 107, 1711-1717. doi: 10.1152/jn.00773. 2011

Sancier, M. L., and Fowler, C. A. (1997). Gestural drift in a bilingual speaker of Brazilian Portuguese and English. J. Phon. 25, 421-436. doi: 10.1006/ jpho.1997.0051

Sato, W., and Yoshikawa, S. (2007). Spontaneous facial mimicry in response to dynamic facial expressions. Cognition 104, 1-18. doi: 10.1016/j.cognition.2006.05.001

Schwartz, J. L., Abry, C., Boë, L. J., and Cathiard, M. A. (2002). "Phonology in a theory of perception-foraction-control," in Phonology: from Phonetics to Cognition, eds J. Durand and B. Lacks (Oxford: Oxford University Press,), 240-280

Schwartz, J. L., Ménard, L., Basirat, A., and Sato, M. (2012). The Perception for Action Control Theory (PACT): a perceptuomotor theory of speech perception. J. Neurolinguist. 25, 336-354. doi: 10.1016/j.jneuroling.2009.12.004

Scott, S. K., and Johnsrude, I. S. (2003). The neuroanatomical and functional organization of speech perception. Trends Neurosci. 26, 100-107. doi: 10.1016/S0166-2236(02)00037-1

Shiller, D. M., Gracco, V. L., and Rvachew, S. (2010). Auditorymotor learning during speech production in 9-11 year-old children. PLoS ONE 5:e12975. doi: 10.1371/journal.pone.0012975

Shiller, D. M., Sato, M., Gracco, V. L., and Baum, S. (2009). Perceptual recalibration of speech sounds following speech motor learning. J. Acoust. Soc. Am. 125, 1103-1113. doi: 10.1121/1.3058638

Shockley, K., Santana, M. V., and Fowler, C. A. (2003). Mutual interpersonal postural constraints are involved in cooperative conversation. J. Exp. Psychol. Hum. Percpt. Perform. 29, 326-332.

Skipper, J. I., Van Wassenhove, V., Nusbaum, H. C., and Small, S. L. (2007). Hearing lips and seeing voices: how cortical areas supporting speech production mediate audiovisual speech perception. Cereb. Cortex 17, 2387-2399. doi: 10.1093/cercor/bhl147

Tian, X., and Poeppel, D. (2010). Mental imagery of speech and movement implicates the dynamics of internal forward models. Front. Psychol. 1:166. doi: 10.3389/fpsyg.2010.00166

Tremblay, S., Shiller, D. M., and Ostry, D. J. (2003). Somatosensory basis of speech production. Nature 423, 866-869. doi: 10.1038/nature01710

Villacorta, V. M., Perkell, J. S., and Guenther, F. H. (2007). Sensorimotor adaptation to feedback perturbations of vowels acoustics and its relation to perception. J. Acoust. Soc. Am. 122, 2306-2319. doi: 10.1121/1.2773966 von Holst, E., and Mittelstaedt, $\mathrm{H}$. (1950). Das Reafferenzprinzip. Wechselwirkungen zwischen Zentralnervensystem und Peripherie. Naturwissenchaften 37, 464-476. doi: 10.1007/BF00622503
Wilson, S. M., and Iacoboni, M. (2006). Neural responses to non-native phonemes varying in producibility: evidence for the sensorimotor nature of speech perception. Neuroimage 33, 316-325. doi: 10.1016/j.neuroimage.2006.05.032

Zwicker, E., and Fastl, H. (1990). Psychoacoustics - Facts and Models. Heidelberg: Springer-Verlag.

Conflict of Interest Statement: The authors declare that the research was conducted in the absence of any commercial or financial relationships that could be construed as a potential conflict of interest.

Received: 21 March 2013; accepted: 20 June 2013; published online: 11 July 2013.

Citation: Sato M, Grabski K, Garnier M, Granjon L, Schwartz J-L and Nguyen $N$ (2013) Converging toward a common speech code: imitative and perceptuomotor recalibration processes in speech production. Front. Psychol. 4:422. doi: 10.3389/fpsyg.2013.00422

This article was submitted to Frontiers in Cognitive Science, a specialty of Frontiers in Psychology.

Copyright (c) 2013 Sato, Grabski, Garnier, Granjon, Schwartz and Nguyen. This is an open-access article distributed under the terms of the Creative Commons Attribution License, which permits use, distribution and reproduction in other forums, provided the original authors and source are credited and subject to any copyright notices concerning any third-party graphics etc. 